\title{
Preparation and Quality Evaluation of Low-fat Mayonnaise by Using Hydrocolloid Gums and Olive Oil
}

\author{
Aaysha Ihsan ${ }^{1 *}$, Hamda Javed ${ }^{2}$ and Muhammad Umar Javed ${ }^{3}$ \\ ${ }^{1}$ National Institute of Food Science and Technology, University of Agriculture, \\ Faisalabad, Pakistan \\ ${ }^{2}$ Department of Computer Science and Technology, University of Sargodha, \\ Pakistan \\ ${ }^{3}$ College of Pastoral Agriculture Science and Technology, Lanzhou University, Gansu \\ Province, China \\ *Corresponding Author: Aaysha Ihsan, National Institute of Food Science and \\ Technology, University of Agriculture, Faisalabad, Pakistan \\ E-mail: aayshaihsan450@gmail.com
}

\begin{abstract}
Commercial mayonnaise contains $70-80 \%$ oil that becomes the reason of many health problems. This study was conducted by keeping in view the most recent trend and its problems. The principal objective of this research was to establish stable mayonnaise with low fat by using hydrocolloid gums (xanthan gum, corn starch) as a fat replacer with olive oil which are also cost effective. So due to health and economic concerns, the formulation of healthier versions of mayonnaise are developing that have low fat with same stability and price like their counterparts. It is also important to properly choose the concentration of your food gum in terms of the consistency of LF mayonnaise, which can result in an elastic gum if you add too much gum. If you add too little gum and the whole water is not bound permanently then, the mayonnaise can appear as a fluffy, airy mass. Treatments T2 (0.50\% XG), T3 (0.75\% XG), T4 (1\% CS) and T7 (XG:CS) showed the better results as compare to traditional full-fat mayonnaise in terms of physical and sensory characteristics. With the increased level of hydrocolloid, calorie contents decreased but high level of gum can also affect overall acceptability of low-fat mayonnaise. This research has significant effect in industrial/commercial level.
\end{abstract}

Keywords: Xanthan Gum (XG); Corn Starch (CS), Olive Oil; Low-fat Mayonnaise

\section{Introduction}

Mayonnaise is commonly use all over the world. In early 1900s, it was commercially produced and most popular in America and also in Japan. It is a semi solid and oil-in-water emulsion which contains $70 \%$ to $80 \%$ fat contents. According to American Heart Association usage of fat in diet should be lower than $30 \%$ of the overall consumed calories. Its low $\mathrm{pH}$ makes it resistant to the microbial spoilage. It is prepared traditionally by mixing different ingredients like vinegar, egg yolk, spices and oil [1]. Egg yolk is main ingredient that is responsible for the stability of mayonnaise and mustard is responsible for the characteristic flavor of mayonnaise because it contains isothiocyanates which are stabilizes in the solution by adding citric acid. Now a day the demand of consumers for food products that are more natural, healthier and nutritional has increased in all over the world. The over consumption of different type of lipids is linked with harmful health effect [2]. Limiting fat consumption should be below $30 \%$ of overall consumed calories according to American Heart Association. So due to health concern of consumers, food industries are now trying to produce low-fat mayonnaise that has the same texture, flavor, color and stability like 
full fat mayonnaise. But the low-fat production is linked with some technical problems like low mouth feel, texture, stability etc. So, to obtain low fat mayonnaise with same quality as the full fat mayonnaise the fat should be replaced by the fat replacers that have various functionalities [3]. There is also need to higher the water contents and low the dispersed phase in emulsion for the creation of low-fat mayonnaise [4]. Many fat replacers were used for stabilization of emulsion and to higher the mayonnaise viscosity. Some of these fat replacers are inulin, pectin, cellulose and some different thickeners [5]. Some most commonly studied fat replacers are xanthan gum and guar gum. Some studies show that various types of gum might show good functional properties when they are use in a combination than of those which used separately [6]. Hydrocolloids are polymer group of polysaccharides with long chains. They act as thickening and gelling agents because of this when hydrocolloids are added in emulsion, the stability and viscosity of water phase increases. Because of that hydrocolloids are suitable for low fat mayonnaise production. There are no satisfactory reports on the application of different hydrocolloid gums especially relevant to xanthan gum and corn starch in a combination. Therefore, this study will investigate the combined and separately effect of both xanthan gum and corn starch gum completely with olive oil for the formulation of low-fat mayonnaise. Both these acts as functional ingredient and also have those properties that are required for stable low-fat mayonnaise like xanthan gum is soluble in cold and hot water in acidic condition. It is also resistant enzymatic degradation [7].

\section{Materials and Methods \\ Materials}

All the raw materials used for the mayonnaise preparation like oil, dried egg yolk, salt, sugar, mustard, xanthan gum and corn starch were purchased from city market of Pakistan. The chemicals citric acid, sodium benzoate and EDTA (ethylene diamine tetra acetic acid) were provided by National Institute of Food Science and Technology, UAF, Pakistan.

\section{Methods}

The recipes of FF (full-fat) mayonnaise as a control treatment and LF (low-fat) mayonnaise are shown in table 1. All treatment of mayonnaise was prepared by using food mixer (T25 digital ultra turrax, IKA, Germany). At first, dried egg yolk was mixed with the water thoroughly for 3 minutes for the fully reconstitute of egg yolk. After that, all powder components (salt, sugar, guar gum, xanthan gum, sodium benzoate and EDTA) and water were added and mixed for almost 4-5 minutes in a rotatory mixer. Then $1 / 3^{\text {rd }}$ of total vinegar was added in it and mixed for 3 minutes. Then oil was added gently into aqueous mixture while mixing. The mixture was mixed with the remaining vinegar and mixed for 4 minutes for harmonization. Filled the mayonnaise in pre-sterilized bottles and sealed airtight at room temperature.

\begin{tabular}{|c|c|c|c|c|c|c|c|c|c|c|}
\hline Ingredients $\%$ & $\left.\mathbf{T}_{\mathbf{0}} \mathbf{( F F}\right)$ & $\left.\mathbf{T}_{\mathbf{1}} \mathbf{( L F}\right)$ & $\left.\mathbf{T}_{\mathbf{2}} \mathbf{( L F}\right)$ & $\left.\mathbf{T}_{\mathbf{3}} \mathbf{( L F}\right)$ & $\mathbf{T}_{\mathbf{4}}(\mathbf{L F})$ & $\mathbf{T}_{\mathbf{5}}(\mathbf{L F})$ & $\mathbf{T}_{\mathbf{6}}(\mathbf{L F})$ & $\mathbf{T}_{\mathbf{7}}(\mathbf{L F})$ & $\mathbf{T}_{\mathbf{8}}(\mathbf{L F})$ & $\mathbf{T}_{\mathbf{9}}(\mathbf{L F})$ \\
\hline Oil $^{*}$ & 75 & 40 & 40 & 40 & 40 & 40 & 40 & 40 & 40 & 40 \\
\hline Water & 7.7 & 42.25 & 42 & 41.75 & 41.5 & 40.5 & 39.5 & 41.25 & 40 & 38.75 \\
\hline Vinegar & 11 & 11 & 11 & 11 & 11 & 11 & 11 & 11 & 11 & 11 \\
\hline Dried Egg yolk & 2 & 2 & 2 & 2 & 2 & 2 & 2 & 2 & 2 & 2 \\
\hline Salt & 2 & 2 & 2 & 2 & 2 & 2 & 2 & 2 & 2 & 2 \\
\hline Sugar & 1 & 1 & 1 & 1 & 1 & 1 & 1 & 1 & 1 & 1 \\
\hline Mustard & 1 & 1 & 1 & 1 & 1 & 1 & 1 & 1 & 1 & 1 \\
\hline EDTA & 0.3 & 0.3 & 0.3 & 0.3 & 0.3 & 0.3 & 0.3 & 0.3 & 0.3 & 0.3 \\
\hline Sodium benzoate & 0.1 & 0.1 & 0.1 & 0.1 & 0.1 & 0.1 & 0.1 & 0.1 & 0.1 & 0.1 \\
\hline Citric Acid & 0.1 & 0.1 & 0.1 & 0.1 & 0.1 & 0.1 & 0.1 & 0.1 & 0.1 & 0.1 \\
\hline Xanthan Gum & - & 0.25 & 0.5 & 0.75 & - & - & - & 0.25 & 0.5 & 0.75 \\
\hline Corn Starch & - & - & - & - & 1 & 2 & 3 & 1 & 2 & 3 \\
\hline
\end{tabular}

Table 1: Formulation of FF and LF mayonnaise treatments.

*FF= Vegetable oil was used in control treatment $\left(\mathrm{T}_{0}\right)$

*LF= Olive oil was used in with Xanthan Gum and Corn starch. 
To investigate the effect of fat replacers with olive oil on the development of low-fat mayonnaise, 9 treatments were prepared from which $\mathrm{T}_{0}$ is control with full fat. Other 8 treatments were prepared by using different level of hydrocolloids (separately and combination) with olive oil.

\section{Compositional analysis}

Moisture, ash, fat, and protein contents were measured as per the official methods of AOAC [8]. Soxhlet apparatus was used to measure the fat content and total soluble solids were measured by Abbe's refractometer. All determinations were carried out in triplicates.

\section{Caloric measurement}

The calorie value Kcal/100g of samples was measured by using bomb caloric meter (Model-IKA C2000).

\section{pH Measurement}

pH determination was done according to AOAC (2006). Double distilled water was used to dilute the sample while $\mathrm{pH}$ meter used for in determining the $\mathrm{pH}$ (Model 827, Metrohm, Switzerland). Buffer solution was used to standardize the $\mathrm{pH}$ meter. Before each reading, $\mathrm{pH}$ meter was standardized with double distilled water.

\section{Water activity measurement}

$A_{w}$ values were measured at a temperature of $25^{\circ} \mathrm{C}$ by using a Hygrolab-2 (rotronic AG, Bassersdrof, Switzerland). A $14 \mathrm{~mm}$ container was filled with the sample and it water activity was measured by lowering the prob (HC2-AW) on container.

\section{Color measurement}

Color of mayonnaise was observed by colorimeter using the method given by Mun S., et al. [9]. Colorimeter was used to check the color range of mayonnaise samples. A color spectrophotometer was used for this study. L* (lightness), a* (redness), b* (yellowness) are color parameters and their values were determined by using the illuminant D65 with measuring area of $8 \mathrm{~mm}$ diameter. The magnitudes for reddish and greenish was expressed with the negative and positive values of a*. Similarly, positive and negative values for $b^{*}$ represents yellow and blue respectively.

\section{Texture measurement}

Texture analyzer was used to evaluate the textural properties of all mayonnaise treatments (CT3, Brookfield, USA) which has $42 \mathrm{~mm}$ diameter cylindrical prob. At first, the acrylic container was filled with the sample, the diameter of container was $42 \mathrm{~mm}$ and $30 \mathrm{~mm}$ in depth. The test was taken at test speed of $1.00 \mathrm{~mm} / \mathrm{s}$ and at $15 \mathrm{~mm}$ of test distance. The disc was returned back to its initial point after the comparison was done. The resulting force helped measuring the time curve, firmness, consistency and adhesiveness. Measurement of firmness was taken as the highest force used.

\section{Sensory evaluation}

Sensory evaluation (color, taste, texture and overall acceptability) was done after all samples were stored at room temperature for one day and 9- Point hedonic scale was used (1 is the least and 9 is the most or highest) and evaluated by panel of 5 trained members [10].

\section{Statistical analysis}

All treatments were triplicated, and one-way analysis of variance (ANOVA) was used to statistically analyze the data. Tukey's test was applied to separate the means when we observed the considerable amount of main effect. 5\% ( $<<0.05)$ was the predetermined adequate level of probability was for all comparisons. All analysis was performed using statistics 7.1.

\section{Results and Discussion}

All treatments of mayonnaise were analyzed to determine it stability by using fat replacer and olive oil.

\section{Compositional analysis}

The determination of moisture, protein, ash, and fat content are mentioned in table 2 . The FF mayonnaise sample has significantly low moisture contents then LF mayonnaise. It can also be seen in table 2. that moisture content decrease with the increasing level of fat substitutes. Furthermore, the decreased level of oil is compensated by increasing the moisture. Water is known to be a major ingredient when replacing fat with carbohydrate-based fat substitutes. The texture of LF mayonnaise is enhanced because water forms a gel-like structure with hydrocolloid gum [11]. Ash contents of FF mayonnaise was low as compared to LF mayonnaise. But the slight change was seen in LF mayonnaise samples due to the use 
of carbohydrate-based fat replacers. According to Su., et al. 2010, in formulation of low-fat mayonnaise, fat replacers is the main cause of increase in moisture and ash content. As expected, higher fat contents were observed in FF mayonnaise as compared to LF mayonnaise. All LF treatments showed slightly decrease in fat due to increase in level of fat replacer. A decreasing trend can be seen in fat between all LF treatment due to increase in level of gums. Overall increase in protein was noticed in all LF treatments. Control treatment has low protein value as compared to other treatment because of the addition of gums which also has protein residue [7]. It is clear from the results that the protein contents became high as the level of gum increase.

\section{Caloric measurement}

Caloric contents of mayonnaise are also given in table 2 . The calorie value of LF mayonnaise was reduced significantly. The decrease in caloric value may be due to the replacement of the oil from FF mayonnaise with water and hydrocolloid gums, which are non-calorie because human digestive tract cannot digest or absorb them [11]. Further fluctuation in treatments of LF calories is due to different level of gums. If the level of gum increase, the caloric value decreased.

\begin{tabular}{|c|c|c|c|c|c|}
\hline Treatment & Moisture & Ash & Fat & Protein & Calories \\
\hline $\mathrm{T}_{0}$ & $15.14^{\mathrm{O}} \pm 0.02$ & $1.05^{\mathrm{N}} \pm 0.01$ & $83.81^{\mathrm{A}} \pm 0.01$ & $1.35^{\mathrm{AB}} \pm 0.02$ & $798.00^{\mathrm{A}} \pm 0.03$ \\
\hline $\mathrm{T}_{1}$ & $76.53^{\mathrm{F}} \pm 0.01$ & $1.08^{\mathrm{MN}} \pm 0.01$ & $56.46^{\mathrm{B}} \pm 0.03$ & $2.51^{\mathrm{AB}} \pm 0.01$ & $525.00^{\mathrm{H}} \pm 0.02$ \\
\hline $\mathrm{T}_{2}$ & $75.12^{\mathrm{L}} \pm 0.02$ & $1.50^{\mathrm{L}} \pm 0.02$ & $53.71^{\mathrm{CD}} \pm 0.01$ & $2.58^{\mathrm{AB}} \pm 0.02$ & $516.00^{\mathrm{I}} \pm 0.03$ \\
\hline $\mathrm{T}_{3}$ & $74.24^{\mathrm{M}} \pm 0.02$ & $1.28^{\mathrm{G}} \pm 0.01$ & $49.38^{\mathrm{E}-\mathrm{G}} \pm 0.01$ & $2.69^{\mathrm{AB}} \pm 0.03$ & $508.00^{\mathrm{J}} \pm 0.01$ \\
\hline $\mathrm{T}_{4}$ & $77.21^{\mathrm{G}} \pm 0.01$ & $1.56^{\mathrm{K}} \pm 0.03$ & $47.64^{\mathrm{GH}} \pm 0.02$ & $2.42^{\mathrm{B}} \pm 0.01$ & $610.00^{\mathrm{C}} \pm 0.03$ \\
\hline $\mathrm{T}_{5}$ & $75.69^{\mathrm{J}} \pm 0.01$ & $1.71^{\mathrm{I}} \pm 0.02$ & $45.63^{\mathrm{H}-\mathrm{J}} \pm 0.01$ & $2.50^{\mathrm{AB}} \pm 0.02$ & $570.00^{\mathrm{E}} \pm 0.02$ \\
\hline $\mathrm{T}_{6}$ & $74.08^{\mathrm{N}} \pm 0.03$ & $1.89^{\mathrm{F}} \pm 0.03$ & $41.33^{\mathrm{LM}} \pm 0.02$ & $2.66^{\mathrm{A}} \pm 0.02$ & $535.00^{\mathrm{G}} \pm 0.03$ \\
\hline $\mathrm{T}_{7}$ & $80.53^{\mathrm{D}} \pm 0.03$ & $1.91^{\mathrm{D}-\mathrm{F}} \pm 0.02$ & $54.55^{\mathrm{BC}} \pm 0.02$ & $2.59^{\mathrm{AB}} \pm 0.02$ & $640.00^{\mathrm{B}} \pm 0.04$ \\
\hline $\mathrm{T}_{8}$ & $78.95^{\mathrm{E}} \pm 0.03$ & $1.93^{\mathrm{B}-\mathrm{E}} \pm 0.02$ & $50.69^{\mathrm{D}-\mathrm{F}} \pm 0.03$ & $2.63^{\mathrm{A}} \pm 0.01$ & $590.00^{\mathrm{D}} \pm 0.02$ \\
\hline $\mathrm{T}_{9}$ & $77.08^{\mathrm{H}} \pm 0.01$ & $1.94^{\mathrm{B}-\mathrm{D}} \pm 0.01$ & $43.53^{\mathrm{J}-\mathrm{L}} \pm 0.01$ & $2.68^{\mathrm{A}} \pm 0.01$ & $545.00^{\mathrm{F}} \pm 0.01$ \\
\hline
\end{tabular}

Table 2: Compositional Analysis of full-fat and low-fat mayonnaise at room temperature.

$$
\begin{gathered}
\mathrm{T}_{0}{ }^{*}=\text { Control treatment with } 75 \% \text { vegetable oil } \\
\text { Calories* }{ }^{*} \mathrm{kcal} / 100 \mathrm{~g} \text {. }
\end{gathered}
$$

pH

According to table 3. pH of FF mayonnaise was lower than lowfat sample. Increase in $\mathrm{pH}$ level depends upon level of fat replacers. As the level of fat replacers increases the $\mathrm{pH}$ values increase. The dilution of the acetic acid while it is in aqueous form of the LF formulations is considered to be responsible for the $\mathrm{pH}$ increase. Moreover, this fluctuation of $\mathrm{pH}$ in LF treatment could be attributed to the attractive and repulsive forces between the polar and nonpolar groups of hydrocolloids and protein. It has been reported that formation of carboxylic groups due to the breakdown of ester groups present in the structure of hydrocolloids contributed to decrease in $\mathrm{pH}[2]$.

\section{Water activity}

The lowest water activity was observed in the control sample that can be seen in table 3. Although an increasing manner was observed in water activity in the LF samples by increasing the level of fat replacer. Various studies indicated that water activity value increased by increasing the concentration of fat replacers. Water has a key role in function of carbohydrate based fat substitutes by forming gel like structure through interaction with the fat replacers that improve texture of LF mayonnaise. Therefore, the increase of water activity can be ascribed to the ability of carbohydrate-based fat replacers to bind and hold water in their structure through hydrogen bond [12]. 


\begin{tabular}{|c|c|c|}
\hline Treatment & $\mathbf{p H}$ & $\mathbf{A}_{\mathbf{w}}$ \\
\hline $\mathrm{T}_{0}$ & $3.95^{\mathrm{H}} \pm 0.02$ & $0.87^{\mathrm{I}} \pm 0.01$ \\
\hline $\mathrm{T}_{1}$ & $4.08^{\mathrm{J}} \pm 0.02$ & $0.95^{\mathrm{HI}} \pm 0.02$ \\
\hline $\mathrm{T}_{2}$ & $4.18^{\mathrm{I}} \pm 0.03$ & $0.98^{\mathrm{E}-\mathrm{H}} \pm 0.01$ \\
\hline $\mathrm{T}_{3}$ & $4.26^{\mathrm{FG}} \pm 0.03$ & $1.00^{\mathrm{D}-\mathrm{E}} \pm 0.03$ \\
\hline $\mathrm{T}_{4}$ & $4.23^{\mathrm{GH}} \pm 0.01$ & $0.96^{\mathrm{G}-\mathrm{I}} \pm 0.02$ \\
\hline $\mathrm{T}_{5}$ & $4.28^{\mathrm{F}} \pm 0.02$ & $0.99^{\mathrm{E}-\mathrm{G}} \pm 0.02$ \\
\hline $\mathrm{T}_{6}$ & $4.35^{\mathrm{E}} \pm 0.01$ & $1.04^{\mathrm{B}-\mathrm{D}} \pm 0.03$ \\
\hline $\mathrm{T}_{7}$ & $4.31^{\mathrm{D}} \pm 0.01$ & $0.95^{\mathrm{HI}} \pm 0.01$ \\
\hline $\mathrm{T}_{8}$ & $4.51^{\mathrm{B}} \pm 0.03$ & $1.02^{\mathrm{C}-\mathrm{E}} \pm 0.01$ \\
\hline $\mathrm{T}_{9}$ & $4.66^{\mathrm{A}} \pm 0.02$ & $1.05^{\mathrm{A}-\mathrm{C}} \pm 0.03$ \\
\hline
\end{tabular}

Table 3: $\mathrm{pH}$ and $\mathrm{A}_{\mathrm{w}}$ values of $\mathrm{FF}$ and LF mayonnaise.

Color measurement

Color parameters, especially $L^{*}$ value (lightness) play an important role in the consumer acceptance. $L^{*}$ value of the LF mayonnaise was low as compared to FF mayonnaise (Table 4). But treatment $\mathrm{T}_{2}, \mathrm{~T}_{3}, \mathrm{~T}_{4}$ and $\mathrm{T}_{7}$ showed good results. Table 4 . indicates that increasing the concentration of xanthan gum and corn starch decreased the $\mathrm{L}^{*}$ value of LF mayonnaise. This decrease in lightness is preferrable and considered good then light shade according to evaluation panel. The $\mathrm{a}^{*}$ values produce no important discrepancy among all FF and LF mayonnaise formulations. The $a^{*}$ values have been expressed in negative units since they imply the existence of a green pigment. The presence of green pigment was similar in both LF mayonnaise and FF mayonnaise this result was also observed by Amin., et al. 2014. The $b^{*}$ value is expressed as positive quantities indicating the existence of yellow pigment. LF mayonnaise had a lower $b^{*}$ value than FF mayonnaise. The $b^{*}$ value of LF decreases with higher content of fat substitutes. It can be understood that hydrocolloid can diminish the color of a particular product. Which can be interpreted that hydrocolloids may dilute the color of the products when protein and hydrocolloids interact with each other. This might also be attributed to the reduction in oil level [7].

\section{Textural analysis}

The addition of gum to the LF formulation is very important to obtain product with good texture properties and high emulsion stability. According to table 5 LF mayonnaise showed higher firmness and adhesiveness than FF mayonnaise. This result is probably due to the increased viscosity of the emulsion by adding hydrocolloid gum to the LF formulation. Hydrocolloid creates a gel-like

\begin{tabular}{|c|c|c|c|}
\hline Treatment & $\mathbf{L}^{*}$ & $\mathbf{a}^{*}$ & $\mathbf{b}^{*}$ \\
\hline $\mathrm{T}_{0}$ & $79.04^{\mathrm{R}} \pm 0.02$ & $-1.51^{\mathrm{I}} \pm 0.01$ & $14.83^{\mathrm{C}-\mathrm{G}} \pm 0.01$ \\
\hline $\mathrm{T}_{1}$ & $77.71^{\mathrm{D}} \pm 0.02$ & $-1.54^{\mathrm{HI}} \pm 0.01$ & $12.43^{\mathrm{AB}} \pm 0.02$ \\
\hline $\mathrm{T}_{2}$ & $76.30^{\mathrm{J}} \pm 0.01$ & $-1.59^{\mathrm{GH}} \pm 0.01$ & $11.35^{\mathrm{E}-\mathrm{H}} \pm 0.01$ \\
\hline $\mathrm{T}_{3}$ & $75.91^{\mathrm{F}} \pm 0.02$ & $-1.60^{\mathrm{EF}} \pm 0.03$ & $10.84^{\mathrm{A}-\mathrm{C}} \pm 0.02$ \\
\hline $\mathrm{T}_{4}$ & $76.95^{\mathrm{P}} \pm 0.03$ & $-1.53^{\mathrm{I}} \pm 0.01$ & $13.54^{\mathrm{B}-\mathrm{E}} \pm 0.02$ \\
\hline $\mathrm{T}_{5}$ & $73.79^{\mathrm{N}} \pm 0.03$ & $-1.55^{\mathrm{G}-} \pm{ }^{\mathrm{I}} 0.02$ & $12.87^{\mathrm{C}-\mathrm{G}} \pm 0.02$ \\
\hline $\mathrm{T}_{6}$ & $72.49^{\mathrm{G}} \pm 0.02$ & $-1.62^{\mathrm{AB}} \pm 0.01$ & $10.68^{\mathrm{GH}} \pm 0.01$ \\
\hline $\mathrm{T}_{7}$ & $77.54^{\mathrm{L}} \pm 0.01$ & $-1.53^{\mathrm{FG}} \pm 0.01$ & $13.54^{\mathrm{A}-\mathrm{C}} \pm 0.02$ \\
\hline $\mathrm{T}_{8}$ & $75.36^{\mathrm{H}} \pm 0.02$ & $-1.49^{\mathrm{EF}} \pm 0.02$ & $11.24^{\mathrm{F}-\mathrm{H}} \pm 0.02$ \\
\hline $\mathrm{T}_{9}$ & $74.39^{\mathrm{B}} \pm 0.02$ & $1.46^{\mathrm{C}-\mathrm{E}} \pm 0.01$ & $9.24^{\mathrm{H}} \pm 0.02$ \\
\hline
\end{tabular}

Table 4: Color measurement of FF and LF mayonnaise.

structure that traps oil droplets that increases viscosity. Identical results were achieved by Nikzade and Tehrani, 2012. He reported that low-fat mayonnaise made from a hydrocolloid mixture had a higher firmness and adhesiveness because of hydrocolloids. But this firmness increases if the level of gum will too high that can cause poor stability.

\begin{tabular}{|c|c|c|}
\hline Treatment & Firmness & Adhesiveness \\
\hline $\mathrm{T}_{0}$ & $2.01^{\mathrm{CD}} \pm 0.02$ & $11.18^{\mathrm{A}-\mathrm{D}} \pm 0.02$ \\
\hline $\mathrm{T}_{1}$ & $2.84^{\mathrm{B}-\mathrm{D}} \pm 0.01$ & $15.20^{\mathrm{A}-\mathrm{D}} \pm 0.01$ \\
\hline $\mathrm{T}_{2}$ & $2.95^{\mathrm{A}-\mathrm{D}} \pm 0.02$ & $17.46^{\mathrm{A}-\mathrm{D}} \pm 0.01$ \\
\hline $\mathrm{T}_{3}$ & $3.09^{\mathrm{A}-\mathrm{C}} \pm 0.02$ & $19.48^{\mathrm{AB}} \pm 0.01$ \\
\hline $\mathrm{T}_{4}$ & $2.98^{\mathrm{B}-\mathrm{D}} \pm 0.01$ & $16.30^{\mathrm{AB}-\mathrm{D}} \pm 0.02$ \\
\hline $\mathrm{T}_{5}$ & $3.35^{\mathrm{A}-\mathrm{D}} \pm 0.02$ & $19.56^{\mathrm{A}-\mathrm{D}} \pm 0.01$ \\
\hline $\mathrm{T}_{6}$ & $3.97^{\mathrm{A}-\mathrm{C}} \pm 0.02$ & $21.55^{\mathrm{AB}} \pm 0.02$ \\
\hline $\mathrm{T}_{7}$ & $3.05^{\mathrm{A}-\mathrm{D}} \pm 0.01$ & $17.49^{\mathrm{A}-\mathrm{D}} \pm 0.02$ \\
\hline $\mathrm{T}_{8}$ & $3.87^{\mathrm{D}} \pm 0.01$ & $19.39^{\mathrm{A}-\mathrm{D}} \pm 0.04$ \\
\hline $\mathrm{T}_{9}$ & $4.98^{\mathrm{AB}} \pm 0.01$ & $23.62^{\mathrm{A}} \pm 0.02$ \\
\hline
\end{tabular}

Table 5: Texture analysis of FF and LF mayonnaise.

\section{Sensory evaluation}

First impression that is perceived by consumers for food product is color. Sensory evaluation was performed after one day storage of all samples at room temperature and 9- Point hedonic scale was used ( 1 is the least and 9 is the most or highest) and evaluated by panel of 5 trained members [10]. Sensory scores of mayonnaise samples with different formulations are shown in Table 6. Color, taste, texture and overall acceptability scores of low-fat samples 
were decreased by increase in the level of gums. The higher the level of gum, resulted in a darker color [2]. The acceptance of mayonnaise with a color, texture indicator that was highly acceptable and preferred by panelists was $\mathrm{T}_{2}(0.50 \% \mathrm{XG}), \mathrm{T}_{3}(0.75 \% \mathrm{XG}), \mathrm{T}_{4}$ ( $1 \% \mathrm{CS}), \mathrm{T}_{7}(0.25 \% \mathrm{XG}: 1 \% \mathrm{CS})$. Higher level of hydrocolloid result in increased viscosity that is unacceptable. Low score in LF sample for texture is due to the insufficient dispersion/hydration of hydrocolloids in the water that creates grainy texture in final product. The given table of sensory evaluation indicated good overall acceptability of LF treatments with balanced level of hydrocolloid because too high and too low level can result in poor texture and unattractive color.

\begin{tabular}{|c|c|c|c|c|}
\hline Treatment & Color & Taste & Texture & $\begin{array}{c}\text { Overall } \\
\text { Acceptability }\end{array}$ \\
\hline $\mathrm{T}_{0}$ & $7.75^{\mathrm{AB}} \pm$ & $7.50^{\mathrm{B}-\mathrm{D}} \pm 0.02$ & $7.00^{\mathrm{A}-\mathrm{E}} \pm$ & $7.50^{\mathrm{A}-\mathrm{E}} \pm 0.02$ \\
& 0.03 & & 0.01 & \\
\hline $\mathrm{T}_{1}$ & $8.25^{\mathrm{B}} \pm$ & $8.00^{\mathrm{A}} \pm 0.02$ & $7.50^{\mathrm{A}} \pm$ & $8.00^{\mathrm{A}} \pm 0.01$ \\
& 0.08 & & 0.02 & \\
\hline $\mathrm{T}_{2}$ & $9.00^{\mathrm{A}} \pm$ & $9.00^{\mathrm{AB}-\mathrm{D}} \pm 0.02$ & $8.75^{\mathrm{C}-\mathrm{E}} \pm$ & $8.70^{\mathrm{E}} \pm 0.02$ \\
& 0.03 & & 0.02 & \\
\hline $\mathrm{T}_{3}$ & $9.00^{\mathrm{A}} \pm$ & $8.50^{\mathrm{D}} \pm 0.01$ & $9.00^{\mathrm{C}-\mathrm{E}} \pm$ & $9.00^{\mathrm{E}} \pm 0.02$ \\
& 0.03 & & 0.01 & \\
\hline $\mathrm{T}_{4}$ & $9.00^{\mathrm{A}} \pm$ & $8.50^{\mathrm{AB}-\mathrm{D}} \pm 0.01$ & $8.75^{\mathrm{A}} \pm$ & $8.75^{\mathrm{A}-\mathrm{C}} \pm 0.01$ \\
& 0.01 & & 0.01 & \\
\hline $\mathrm{T}_{5}$ & $7.00^{\mathrm{AB}} \pm$ & $6.70^{\mathrm{AB}} \pm 0.02$ & $6.75^{\mathrm{A}-\mathrm{E}} \pm$ & $6.50^{\mathrm{A}-\mathrm{E}} \pm 0.02$ \\
& 0.03 & & 0.01 & \\
\hline $\mathrm{T}_{6}$ & $5.00^{\mathrm{AB}} \pm$ & $6.75^{\mathrm{B}-\mathrm{D}} \pm 0.01$ & $5.25^{\mathrm{A}-\mathrm{D}} \pm$ & $6.00^{\mathrm{B}-\mathrm{E}} \pm 0.02$ \\
& 0.02 & & 0.02 & \\
\hline $\mathrm{T}_{7}$ & $9.00^{\mathrm{A}} \pm$ & $8.75^{\mathrm{A}} \pm 0.01$ & $9.00^{\mathrm{AB}} \pm$ & $9.00^{\mathrm{A}} \pm 0.02$ \\
& 0.02 & & 0.02 & \\
\hline $\mathrm{T}_{8}$ & $6.50^{\mathrm{AB}} \pm$ & $6.75^{\mathrm{A}-\mathrm{D}} \pm 0.01$ & $5.50^{\mathrm{A}-\mathrm{E}} \pm$ & $7.00^{\mathrm{E}} \pm 0.02$ \\
& 0.02 & & 0.03 & \\
\hline $\mathrm{T}_{9}$ & $5.00^{\mathrm{B}} \pm$ & $6.00^{\mathrm{B}-\mathrm{D}} \pm 0.03$ & $4.50^{\mathrm{DE}} \pm$ & $4.00^{\mathrm{E}} \pm 0.01$ \\
& 0.02 & & 0.01 & \\
\hline & & & & \\
\hline
\end{tabular}

Table 6: Sensory Evaluation of FF and LF mayonnaise.

\section{Conclusion}

The results that are statistically analyzed demonstrated that LF mayonnaise showed good textural, physical and sensory characteristics then FF mayonnaise. Best results were given by LF mayonnaise prepared by low level of hydrocolloid separately and in combination with olive oil. But high level of hydrocolloid can result in poor stability especially in terms of texture and color. These research shows that hydrocolloid plays an important role in LF mayonnaise stability, which is cost effective and have functional properties.

\section{Bibliography}

1. Hosseinvand A., et al. Biointerface Research in Applied Chemistry (2019).

2. Johary N., et al. "Effect of basil seed gum and tracaganth gum as fat replacers on physicochemical, antioxidant and sensory properties of low-fat mayonnaise". International Journal of Science and Engineering Invention 4 (2015): 51-57.

3. Nikzade V., et al. "Optimization of low-cholesterol-low-fat mayonnaise formulation: Effect of using soy milk and some stabilizer by a mixture design approach". Food Hydrocolloids 28 (2012): 344-352.

4. Aslanzadeh M., et al. "Rheological properties of low fat mayonnaise with different levels of modified wheat bran". Journal of Food Bioscience and Technology 2 (2012): 27-34.

5. Evanuarini H and Susilo A. "The Quality of Low Fat Mayonnaise Using Banana Peel Flour as Stabilizer". In IOP Conference Series: Earth and Environmental Science 478.1 (2020): 012091.

6. Su H P., et al. "Development of low-fat mayonnaise containing polysaccharide gums as functional ingredients". Journal of the Science of Food and Agriculture 90 (2010): 806-812.

7. Yüceer M., et al. "Comparison of flow behavior and physicochemical characteristics of low-cholesterol mayonnaises produced with cholesterol-reduced egg yolk". The Journal of Applied Poultry Research 25 (2016): 518-527.

8. AOAC. Official Methods of Analysis. 18th Ed. Association of Official Analytical Chemists. Arlington, USA (2006).

9. Mun S., et al. "Development of reduced-fat mayonnaise using $4 \alpha$ GTase-modified rice starch and xanthan gum". International Journal of Biological Macromolecules 44 (2009): 400-407. 
10. Worrasinchai S., et al. “ $\beta$-Glucan prepared from spent brewer's yeast as a fat replacer in mayonnaise". Food Hydrocolloids 20 (2006): 68-78.

11. Amin MHH., et al. "Development of low fatmayonnaise containing different types and levels of hydrocolloid gum". Journal of Agroalimentary Processes and Technologies 20 (2014): 54-63.

12. Hosseinvand A and Sohrabvand S. "Physicochemical, textural and sensory evaluation of reduced-fat mustard sauce formulation prepared with Inulin, Pectin and $\beta$-glucan". Croatian Journal of Food Science and Technology 8 (2016): 46-52.

\section{Assets from publication with us}

- Prompt Acknowledgement after receiving the article

- Thorough Double blinded peer review

- Rapid Publication

- Issue of Publication Certificate

- High visibility of your Published work

Website: www.actascientific.com/

Submit Article: www.actascientific.com/submission.php

Email us: editor@actascientific.com

Contact us: +919182824667 